\title{
Activities and Participation in the First 6 Months After Mild Traumatic Brain Injury in Children and Adolescents
}

Citation for published version (APA):

Renaud, M. I., van de Port, I. G. L., Catsman-Berrevoets, C. E., Jellema, K., Lambregts, S. A. M., \& van Heugten, C. M. (2020). Activities and Participation in the First 6 Months After Mild Traumatic Brain Injury in Children and Adolescents. Journal of Head Trauma Rehabilitation, 35(6), E501-E512. https://doi.org/10.1097/HTR.0000000000000584

Document status and date:

Published: 01/01/2020

DOI:

10.1097/HTR.0000000000000584

Document Version:

Publisher's PDF, also known as Version of record

\section{Document license:}

Taverne

Please check the document version of this publication:

- A submitted manuscript is the version of the article upon submission and before peer-review. There can be important differences between the submitted version and the official published version of record.

People interested in the research are advised to contact the author for the final version of the publication, or visit the DOI to the publisher's website.

- The final author version and the galley proof are versions of the publication after peer review.

- The final published version features the final layout of the paper including the volume, issue and page numbers.

Link to publication

\footnotetext{
General rights rights.

- You may freely distribute the URL identifying the publication in the public portal. please follow below link for the End User Agreement:

www.umlib.nl/taverne-license

Take down policy

If you believe that this document breaches copyright please contact us at:

repository@maastrichtuniversity.nl

providing details and we will investigate your claim.
}

Copyright and moral rights for the publications made accessible in the public portal are retained by the authors and/or other copyright owners and it is a condition of accessing publications that users recognise and abide by the legal requirements associated with these

- Users may download and print one copy of any publication from the public portal for the purpose of private study or research.

- You may not further distribute the material or use it for any profit-making activity or commercial gain

If the publication is distributed under the terms of Article $25 \mathrm{fa}$ of the Dutch Copyright Act, indicated by the "Taverne" license above, 


\title{
Activities and Participation in the First 6 Months After Mild Traumatic Brain
} Injury in Children and Adolescents

\author{
M. Irene Renaud, PhD; Ingrid G. L. van de Port, PhD; \\ Coriene E. Catsman-Berrevoets, MD, PhD; Korné Jellema, MD, PhD; \\ Suzanne A. M. Lambregts, drs; Caroline M. van Heugten, PhD
}

\begin{abstract}
Objective: To investigate the natural course of activities and participation of children up to 6 months after a mild traumatic brain injury (mTBI). Methods: A prospective longitudinal cohort study with complete data sets of 231 children diagnosed with mTBI and their caregivers. Main Measures: Activities and participation assessed with the Child and Adolescent Scale of Participation (CASP) and the Children's Assessment of Participation and Enjoyment (CAPE) measured at 2 weeks, 3 months, and 6 months post-mTBI. Because of a ceiling effect, the primary outcome measure (CASP) was divided into deviant (not maximum score) or full functioning. Results: Friedman's, Cochran's $Q$, and McNemar's tests (CASP) and repeated-measures analyses of variance (CAPE) showed significant increases in activities and participation between 2 weeks and 3 and 6 months after mTBI. Based on the parents' perspective, $67 \%$ of the children returned to full functioning at 6 months postinjury, with only $38 \%$ of the children describing themselves as functioning at their premorbid level. Discussion: Findings indicate that most children return to maximum level of activities and participation over time after mTBI. In a substantial number of children, however, the level of activities and participation at 6 months postinjury is evaluated as lower than that of peers. The importance of investigating predictors for child and caregiver perspectives is emphasized. Key words: activities and participation, children, domains, mild traumatic brain injury, outcome, settings
\end{abstract}

Author Affiliations: Revant Rehabilitation Centre, Breda, the Netherlands (Drs Renaud, van de Port, and Lambregts); Department of Neuropsychology and Psychopharmacology, Maastricht University, Maastricht, the Netherlands (Drs Renaud and van Heugten); Limburg Brain Injury Center, Maastricht, the Netherlands (Drs Renaud and van Heugten); Departments of Paediatric Neurology (Dr Catsman-Berrevoets) and Rehabilitation Medicine (Dr Lambregts), Erasmus University Hospital/Sophia Children's Hospital, Rotterdam, the Netherlands; Department of Neurology, Haaglanden Medical Centre, the Hague, the Netherlands (Dr Jellema); and School for Mental Health and

Neuroscience, Maastricht University Medical Centre, Maastricht, the Netherlands (Dr van Heugten).

The study was funded by the Johanna Kinderfonds (award no. 2012/00401552) and the Revalidatiefonds (award No. R2012175). The authors acknowledge the following: Brains Ahead! Research group: N. Bovens from Maastricht University and Revant Rehabilitation Centre from Rijnstate Hospital; K. van Dijk, H. Hendricks, and D. Rijpsma from Hospital Gelderse Vallei; T. Oosterveld-Bonsma, B. Kievit, and E. Peeters from Medical Centre Haaglanden and Haga Hospital; J. F. de Rijk-van Andel from Amphia Hospital, S. te Winkel from Groot-Klimmendaal Rehabilitation Centre, F. van Markus-Doornbosch from Sophia Rebabilitation Centre, and R. Pangalila from Rijndam Rehabilitation Centre.

The authors declare no conflicts of interest.

Corresponding Author: Caroline M. van Heugten, PhD, Department of Neuropsychology and Psychopharmacology, Faculty of Psychology and Neuroscience, Maastricht University, PO Box 616, 6200 MD Maastricht, the Netherlands (caroline.vanbeugten@maastrichtuniversity.nl).

DOI: 10.1097/HTR.0000000000000584
TRAUMATIC BRAIN INJURIES (TBIs) are reported to be the most common cause of disability or death in children, adolescents, and young adults. ${ }^{1}$ Emergency departments in the United States triage nearly half a million children with TBI annually, of which approximately $80 \%$ are of mild severity. ${ }^{2,3}$ The incidence of mild traumatic brain injury (mTBI) in children between 6 and 18 years old in the emergency department of Dutch hospitals is estimated to be 282 per 100000 per year. ${ }^{4}$ While most children with mTBI recover completely, approximately $20 \%$ suffer from a variety of postconcussive symptoms up to 6 months postinjury or longer. ${ }^{5-9}$ These children may experience limitations in daily life activities and societal participation in the long term. ${ }^{10,11}$ Daily life activities and participation can be considered in different domains such as social, recreational, and sports and in different settings such as at home, in school, or in the community. Both terms are common within framework of the International Classification of Functioning (ICF; World Health Organization). Activities and participation can be further considered from different perspectives such as the child's self-report or the parents/caregivers by proxy report.

The course of activities and participation after brain injury has been investigated in several studies with mixed 
samples of persons with TBI and/or samples including children with acquired brain injury (ABI) without differentiating for mTBI. ${ }^{12-18}$ Only 2 studies investigated the course of activities and participation over time in a sample of children with mTBI. ${ }^{19,20}$ In one study, children's activities and participation decreased during the first 3 months after injury and increased thereafter to full recovery up to 3 years postinjury. ${ }^{19}$ In the other study, participation of children increased up to 12 months in several activity domains such as recreational, active physi$\mathrm{cal}$, and social activities but not in skill-based and selfimprovement activities. ${ }^{20}$ These studies were based on caregiver reports only ${ }^{19}$ or lacked evaluation of participation in different settings such as at home, in school, and in the community. ${ }^{20}$ Since children with TBI in general seem to provide more positive evaluation of their level of activities and participation than their caregivers, it is important to consider both perspectives. ${ }^{21}$ Activities and participation can be measured across settings and for several activity domains, which may produce different profiles: a child may, for instance, have problems in social activities but not in recreational activities and may participate fully at home but not at school. ${ }^{22}$ Activities and participation are very important for the development of a child, since they help children acquire different skills and competencies, grow physically and cognitively, develop their own identity, and set their life goals. ${ }^{23}$ No study has combined the investigation of the course of activities and participation both in different settings and for several activity domains, with respect to the perception of both the caregivers and the child in a large sample of children with mTBI. Furthermore, it is unknown how the course of activities and participation in different settings and in several activity domains is related.

Therefore, the aim of this study was to assess the course of activities and participation after mTBI longitudinally in children in different settings and in several activity domains, using both caregiver reports and selfreports. We expected that activities and participation in different settings and for several activity domains would be lowest at 2 weeks after mTBI, increase up to 3 months, and stabilize at 6 months postinjury. Furthermore, we expected that children would evaluate their own level of activities and participation more positively than their caregivers would. Finally, we expected that the course of activities and participation in different settings and in several activity domains over time after mTBI in children would be positively related.

\section{METHODS}

\section{Design}

This study is part of the larger Brains Ahead! study of activities and participation of children after $\mathrm{mTBI},{ }^{11}$ approved by the medical ethics committee of Erasmus Uni- versity Hospital and by all local committees of the participating hospitals (MEC-2015-047, NL51968.078.14). The Brains Ahead! study consists of a multicenter prospective longitudinal cohort study with a nested randomized controlled trial (RCT); the study design and procedure are published in detail. ${ }^{11}$ In the RCT, the effect of an early psychoeducational intervention is evaluated in comparison with usual care. As the goal of the current analysis is to examine natural recovery after childhood mTBI, participants randomized into the intervention group of the RCT were excluded from the current analysis.

\section{Setting}

All children aged 6 to 18 years who presented with mTBI at the emergency departments of 8 Dutch hospitals between May 2015 and December 2017 and their caregiver(s) were eligible for participation.

\section{Participants}

Children were included if they sustained an mTBI according to the criteria of the American Congress of Rehabilitation Medicine and the World Health Organization Collaborating Centre for Neurotrauma Task Force on Mild Traumatic Brain Injury. ${ }^{24}$ Exclusion criteria were as follows: (1) having a previous objectified head trauma, (2) having progressive neurological problems or disease, (3) attending a day care center or school for cognitively impaired children, and (4) having insufficient knowledge of the Dutch language (child or caregivers) to be able to respond to questions. The caregivers were defined as parents or guardians. There were no further exclusion criteria for caregivers.

\section{Procedure}

After written informed consent was obtained, the baseline measurement $\left(T_{0}\right)$ was scheduled at 2 weeks postinjury. Further measurements took place at $3\left(T_{1}\right)$ and $6\left(T_{2}\right)$ months postinjury. All measurements were administered at the participant's home in the presence of the researcher who gave instructions, prevented missing data as much as possible by checking the filled out questionnaires, and prevented false respondent bias by ensuring the child and the caregiver filled out the questionnaires independently.

\section{Measures}

All instruments have sound psychometric properties and are recommended for evaluating activities and participation after childhood brain injury. ${ }^{22,25-29}$

Several demographic (eg, child's gender, age of the child at injury, parental socioeconomic status [SES], and preinjury behavioral functioning of the child) and 
injury-related (eg Glasgow Coma Scale [GCS] score, loss of consciousness [LOC], posttraumatic amnesia [PTA], and cause of injury) variables were collected from the patient files and at $T_{0}$. The Child Behavior Checklist (CBCL) was filled out on preinjury functioning at baseline $\left(T_{0}\right)$. The CBCL is a 113 -item questionnaire that measures cognitive and behavioral problems and skills in children on a 3-point scale: 0 , never; 1 , sometimes; or 2, often. ${ }^{25}$ The CBCL provides a Total Behavior Problem Score $(T=50, S D=15)$. For the Total Scale, a score of more than 60 can be considered impaired (61-69, mildly impaired; $>70$, severely impaired). ${ }^{25}$

\section{Child and Adolescent Scale of Participation}

Levels of activities and participation were measured in different settings with the Child and Adolescent Scale of Participation (CASP caregiver and CASP self-report). The CASP is a 20 -item questionnaire designed specifically to measure participation in children with $A B I$, according to the components of the International Classification of Functioning, Disability and Health for Children and Youth (ICF-CY). ${ }^{22,26,30}$ The CASP can be filled out by caregivers for children aged 6 to 18 years, and the selfreport can be filled out by children aged 10 to 18 years. The CASP items are added to obtain a total score. In addition, the items are categorized to obtain subscores for the following settings: home, community, school, and environment. The CASP is scored on a 4-point scale: 1 , age-appropriate; 2 , slightly impaired; 3 , heavily impaired; and 4, not capable. Summary scores are created by summing the item responses, dividing this number by the maximum possible score, and multiplying this number by 100 to conform to a 100 -point scale. The total score range is therefore 25 to 100 , with a higher score representing better outcome. Missing and "not applicable" scores were not included in the scoring.

\section{Children's Assessment of Participation and Enjoyment}

Levels of activities and participation were measured and for several domains of activities with the Children's Assessment of Participation and Enjoyment (CAPE selfreport). The CAPE is a 55-item questionnaire that can be filled out by children aged 6 to 18 years. It measures diversity in recreational (12 items), active physical (13 items), social (10 items), skill-based (10 items), and selfimprovement activity (10 items) domains and can be scored in binary fashion as follows: 0 , the activity was not performed; or 1, the activity was performed. ${ }^{27,28}$ The total score range is 0 to 55 , with higher scores indicating more participation in activities. The range per activity domain differs: recreational (0-12), physical activity (013), and social, skill-based, and self-improvement (0-10). Diversity in activity domains measured with the CAPE differs on the basis of the child's age, with certain CAPE items being more age-appropriate for younger children (eg, playing with toys) and other items being more ageappropriate for older children (eg, having a paid job). Therefore, participants are not expected to score a maximum of 55 on the CAPE. ${ }^{28}$ In this study, the CAPE was filled out about the performed activities from the time since injury up to $T_{0}$, and at $T_{1}$ and $T_{2}$ it was filled out about the performed activities in the month prior to the measurement.

\section{Statistical analysis}

Descriptive statistics were used to describe baseline variables and outcomes. Means (standard deviations [SDs]) or medians (ranges) were reported depending on the distribution of the data.

Since outcome data on activities and participation for the CASP caregiver and CASP self-report were not normally distributed, Friedman's tests were used to investigate the course of activities and participation in different settings over time postinjury (ie, 2 weeks and 3 and 6 months after mTBI). Since a ceiling effect on the CASP can be suspected, and because scores on the CASP are given on the basis of the child's functioning with regard to the injury and in comparison with age-related peers, we dichotomized the total and setting scores of the CASP into the following: 0 , deviant functioning (any score below 100); and 1, full functioning in comparison with their healthy/noninjured age-related peers. ${ }^{15,22,26}$ The dichotomized scores were examined over time with Cochran's $Q$ tests and McNemar's tests (significant level set at $P<.05$ ).

Outcome data on activities and participation in several activity domains over time postinjury, measured with the CAPE, were normally distributed and therefore analyzed with repeated-measures analysis of variance. If a significant difference $(P<.05)$ was found between the 3 time points, Wilcoxon's signed-rank test (significant level set at $P<.05$ ) for CASP scores and Levene's test with Bonferonni correction (LSD $P$ value for significance $<.0167$ ) for CAPE scores were used to determine changes over time. ${ }^{11,31}$

To examine whether children evaluate their own levels of activities and participation more positively than their caregivers, comparisons between caregivers and children were made for CASP reports of children aged 10 to 18 years with Wilcoxon's signed-rank tests and with McNemar's tests for the dichotomized data.

The relation between the course of activities and participation in different settings (CASP) and the course of domains (CAPE) over time after mTBI was examined with correlation coefficients (Spearman $\rho$ ) at $T_{0}, T_{1}$, and $T_{2}$ and for the change score between $T_{0}$ and $T_{2}$ for the CASP and the CAPE. Because the CAPE was filled out by children and not by caregivers and the self-report of 
the CASP was filled out by children aged 10 to 18 years and not by younger children, we used only the data sets of children aged 10 to 18 years to examine this relationship. We considered correlation coefficients to be weak if less than 0.3 , moderate if between 0.3 and 0.5 , and strong if more than 0.5 (significant level set at $P<.05$ ). ${ }^{32}$

Since there was a small number $(N=10)$ of participants with incomplete data (eg, dropped out of the study or skipped a measurement due to holiday), we decided to work only with complete data sets. Statistical analyses were performed using IBM SPSS Statistics for Windows, version 24.0.

\section{RESULTS}

\section{Sample characteristics}

A total of 698 children with mTBI were considered for participation in the study, of whom 140 were excluded on the basis of the exclusion criteria (see Figure 1). Furthermore, a total of 257 persons did not participate, of which the vast majority $(n=168)$ could not be reached. Finally, 60 participants who received the Brains Ahead! intervention were excluded from the analyses. Complete data sets were available for 231 children.

Sociodemographic, injury-related, and preinjury characteristics showed that the sample consisted of more boys than girls and the mean age was 11.4 years (see
Table 1). The vast majority of the sample presented a high SES and normal preinjury behavioral functioning. Most children sustained mTBI due to sports and traffic accidents, scored a GCS score of 15 and a PTA of less than 1 hour, and about half of the sample experienced LOC.

\section{The course of activities and participation over time after $\mathrm{mTBI}$ in different settings}

Descriptive results indicated that the scores on the CASP increased for total and domain scores over time postinjury (see Table 2). Friedman's tests showed that the increase in scores on the CASP between $T_{0}$ and $T_{2}$ was significant $(P<.000)$ for total and all domain scores. Wilcoxon's signed-rank tests revealed that total and all domain CASP scores increased significantly $(P<$ .000) between $T_{0}$ and $T_{1}$ and between $T_{0}$ and $T_{2}$ but not between $T_{1}$ and $T_{2}$ except for total activities based on CASP caregiver results for children aged 6 to 18 years $(P=.049)$ and for activities at home based on CASP caregiver results for children aged 6 to 18 years $(P=$ $.001)$ and for children aged 10 to 18 years $(P=.023)$ (see the Appendix).

Analyses of the dichotomized CASP scores showed that at $T_{0}$, between $5.2 \%$ and $25.5 \%$ (depending on the perspective chosen) of the participants scored a maximum total CASP score (see Table 3 ). At $T_{1}$, between

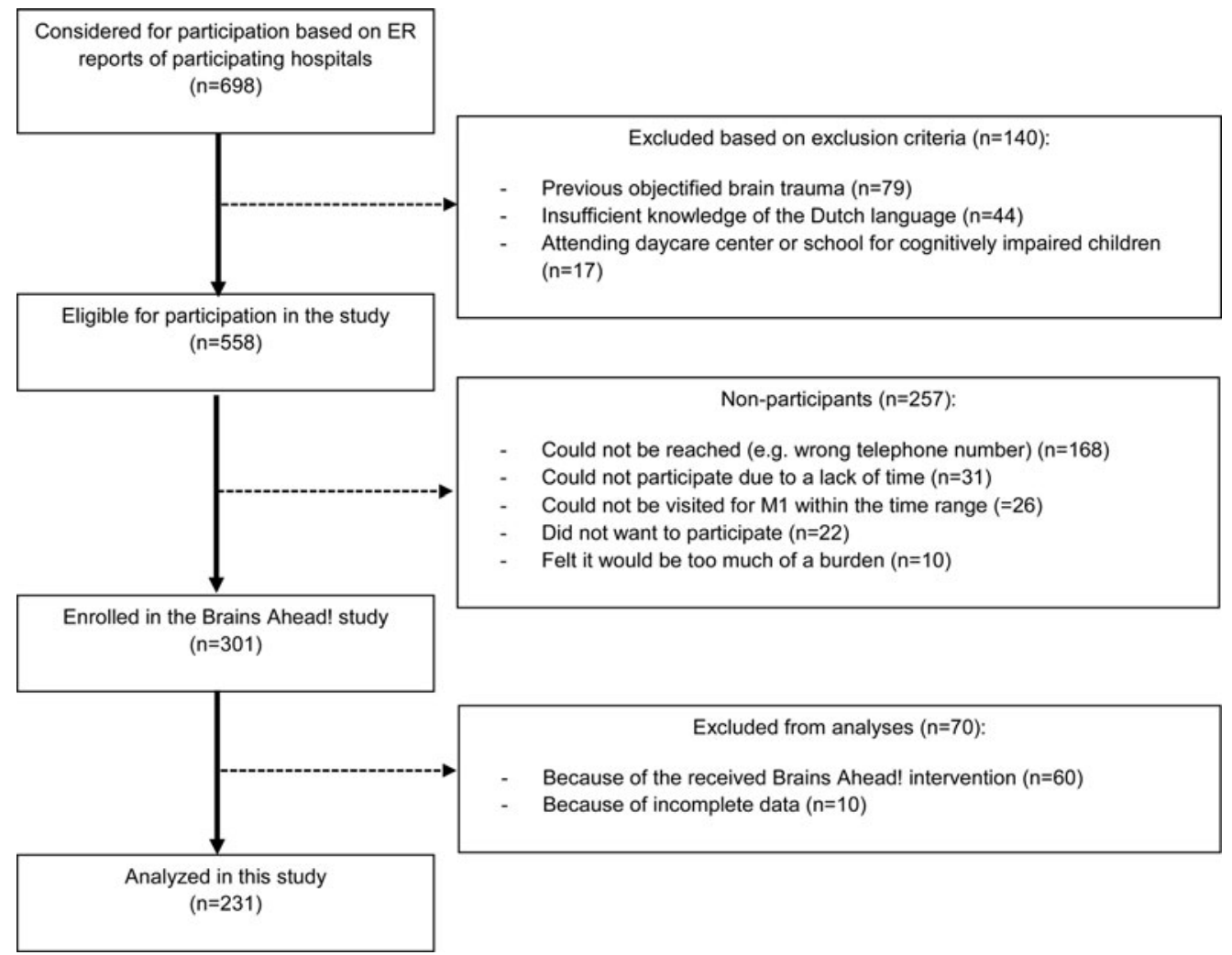

Figure 1. Flow of participants. ER indicates emergency department. 
TABLE 1 Sociodemographic and injury-related characteristics $(\mathrm{N}=231)$

\begin{tabular}{|c|c|c|}
\hline Characteristics & $n(\%)$ & Mean (SD) \\
\hline \multicolumn{3}{|l|}{ Demographics } \\
\hline Child gender: male & $151(65.4)$ & \\
\hline $\begin{array}{l}\text { Child age at injury in } \\
\text { years }\end{array}$ & $231(100)$ & $11.4(3.3)$ \\
\hline Range (Min-Max) & $6-17$ & \\
\hline \multicolumn{3}{|l|}{$\begin{array}{l}\text { Range (IVIn-IVIax) } \\
\text { SES }\end{array}$} \\
\hline Low & $53(22.9)$ & \\
\hline Average & $41(17.7)$ & \\
\hline High & 137 (59.3) & \\
\hline Preinjury behavioral & & $50(10)$ \\
\hline Normal score & $192(83.1)$ & \\
\hline Mild impaired & $29(12.6)$ & \\
\hline Severe impaired & $10(4.3)$ & \\
\hline \multicolumn{3}{|l|}{ Injury-related } \\
\hline \multicolumn{3}{|l|}{ GCS score } \\
\hline 13 & $8(3.5)$ & \\
\hline 14 & $37(16.0)$ & \\
\hline \multirow{2}{*}{\multicolumn{3}{|c|}{ LOC duration }} \\
\hline & & \\
\hline None & $117(50.6)$ & \\
\hline$<2 \min$ & $69(29.9)$ & \\
\hline $2-5 \mathrm{~min}$ & $33(14.3)$ & \\
\hline$>5 \mathrm{~min}$ & $12(5.2)$ & \\
\hline \multicolumn{3}{|l|}{ PTA duration } \\
\hline None & $50(21.6)$ & \\
\hline$<1 \mathrm{~h}$ & $120(51.9)$ & \\
\hline $1-2 \mathrm{~h}$ & $18(7.8)$ & \\
\hline $2-6 \mathrm{~h}$ & $30(13.0)$ & \\
\hline $6-12 \mathrm{~h}$ & $5(2.2)$ & \\
\hline $12-18 \mathrm{~h}$ & $1(0.4)$ & \\
\hline $18-24 \mathrm{~h}$ & $7(3.0)$ & \\
\hline \multicolumn{3}{|l|}{ Cause of injury } \\
\hline Sports accident & $72(31.2)$ & \\
\hline Traffic accident & $68(29.4)$ & \\
\hline $\begin{array}{l}\text { Outdoor play } \\
\text { accident }\end{array}$ & $48(20.8)$ & \\
\hline $\begin{array}{l}\text { Accident at } \\
\text { school/work }\end{array}$ & $22(9.5)$ & \\
\hline Accident at home & $13(5.6)$ & \\
\hline Physical abuse & $5(2.2)$ & \\
\hline Other & $2(0.9)$ & \\
\hline
\end{tabular}

Abbreviations: GCS, Glasgow Coma Scale; LOC, loss of consciousness; PTA, posttraumatic amnesia; SES, caregiver's socioeconomic status.

a Measured at baseline; behavioral functioning with the Child Behavior Checklist T-scores.

$39.4 \%$ and $61.9 \%$ and at $T_{2}$ between $36.1 \%$ and $66.2 \%$ reached the maximum score. Cochran's $Q$ tests showed that the number of children with full functioning scores on the CASP increased significantly $(P<.000)$ over time postinjury for all total and domain scores (see Table 4). McNemar's tests revealed that the number of children with full functioning scores on the CASP increased significantly $(P<.000)$ for all total and domain CASP scores between $T_{0}$ and $T_{1}$ and between $T_{0}$ and $T_{2}$ but not between $T_{1}$ and $T_{2}$ except for activities at home $(P=$ $.001)$ and in the community $(P=.024)$ according to CASP caregiver results for children aged 6 to 18 years (see Table 4).

\section{The course of activities and participation in several activity domains over time post-mTBI}

Descriptive results indicate that the scores on the CAPE increased for total and domain scores over time postinjury (see Table 5). Repeated-measures analyses of variance showed a significant increase in the CAPE score over time between $T_{0}$ and $T_{2}$ for all total and domain scores (see Table 6). Post hoc analyses showed that all total and domain CAPE scores increased significantly $(P<$ .000) between $T_{0}$ and $T_{1}$ and between $T_{0}$ and $T_{2}$ but not between $T_{1}$ and $T_{2}$ except for recreational activities, where a significant $(P=.005)$ decrease was reported.

\section{Comparisons between caregivers' reports and children's self-reports on activities and participation in different settings}

Table 3 shows that, with regard to caregiver reports for children aged 10 to 18 years, $63.9 \%$ followed a course with complete recovery at $T_{2}$, while with regard to the CASP self-report, only $36.1 \%$ did so. Wilcoxon's signedrank tests for continuous data and McNemar's tests for dichotomized data revealed that caregivers tend to score their child's total activities and participation level more positively than the children themselves at $T_{0}(z=-3.84$, $P<.000$, and $\left.\chi_{155}^{2}=16.69, P<.000\right)$, at $T_{1}(z=-5.36$, $P<.000$, and $\left.\chi_{155}^{2}=17.65, P<.000\right)$, and at $T_{2}(z=$ $-6.34, P<.000$, and $\left.\chi_{155}^{2}=32.07, P<.000\right)$.

\section{The relation of the course of activities and participation in different settings with the course of activities and participation in activity domains}

Activities and participation in different settings (CASP) and several activity domains (CAPE) for children aged 10 to 18 years were measured at 3 time points. There was a significant moderate positive correlation $\left(r_{\mathrm{s}}=0.345, P<.000\right)$ at $T_{0}$, a nonsignificant weak positive correlation $\left(r_{\mathrm{s}}=0.156, P=.052\right)$ at $T_{1}$, and a nonsignificant weak positive correlation $\left(r_{\mathrm{s}}=0.116, P=\right.$ $.151)$ at $T_{2}$. Change scores showed a mean difference of 11.81 ( $S D=16.46$; range, -58.75 to 61.25 ) for scores on the CASP self-report for children aged 10 to 18 years between $T_{0}$ and $T_{2}$ and a mean difference of 5.89 ( $\mathrm{SD}=$ 5.78; range, -13.00 to 26.00 ) for scores on the CAPE for children aged 10 to 18 years between $T_{0}$ and $T_{2}$. Correlation coefficients (Spearman $\rho$ ) of these change scores showed a significant weak positive correlation between the change score of activities and participation in different settings and the change score of activities and participation in activity domains $\left(r_{\mathrm{s}}=0.287, P<.000\right)$.

www.headtraumarehab.com 
TABLE 2 Outcome on activities and participation in different settings over time post-mTBI

\begin{tabular}{|c|c|c|c|c|c|}
\hline CASP Setting & $\begin{array}{c}T_{0} \\
\text { Median } \\
\text { (Range) }\end{array}$ & $\begin{array}{c}T_{1} \\
\text { Median } \\
\text { (Range) }\end{array}$ & $\begin{array}{c}T_{2} \\
\text { Median } \\
\text { (Range) }\end{array}$ & $\begin{array}{l}\text { Friedman } \\
\quad \chi^{2} P\end{array}$ & Kendall's $W$ \\
\hline \multicolumn{6}{|c|}{ Caregiver report 6-18 $(N=231)$} \\
\hline Total & $\begin{array}{c}93.75 \\
(82.50-100.00)\end{array}$ & $\begin{array}{c}100.00 \\
(97.50-100.00)\end{array}$ & $\begin{array}{c}100.00 \\
(98.68-100.00)\end{array}$ & $\begin{array}{r}182.16 \\
<.000\end{array}$ & 0.394 \\
\hline At home & $\begin{array}{c}95.83 \\
(87.50-100.00)\end{array}$ & $\begin{array}{c}100.00 \\
(100.00-100.00)\end{array}$ & $\begin{array}{c}100.00 \\
(100.00-100.00)\end{array}$ & $\begin{array}{r}126.86 \\
<.000\end{array}$ & 0.275 \\
\hline In the community & $\begin{array}{c}93.75 \\
(75.00-100.00)\end{array}$ & $\begin{array}{c}100.00 \\
(100.00-100.00)\end{array}$ & $\begin{array}{c}100.00 \\
(100.00-100.00)\end{array}$ & $\begin{array}{l}140.09 \\
<.000\end{array}$ & 0.303 \\
\hline At school & $\begin{array}{c}95.00 \\
(85.00-100.00)\end{array}$ & $\begin{array}{c}100.00 \\
(100.00-100.00)\end{array}$ & $\begin{array}{c}100.00 \\
(100.00-100.00)\end{array}$ & $\begin{array}{l}148.36 \\
<.000\end{array}$ & 0.321 \\
\hline In the environment & $\begin{array}{c}95.00 \\
(80.00-100.00)\end{array}$ & $\begin{array}{c}100.00 \\
(95.00-100.00)\end{array}$ & $\begin{array}{c}100.00 \\
(95.00-100.00)\end{array}$ & $\begin{array}{c}121.44 \\
<.000\end{array}$ & 0.263 \\
\hline \multicolumn{6}{|c|}{ Caregiver report $10-18(N=155)$} \\
\hline Total & $\begin{array}{c}91.25 \\
(81.25-98.75)\end{array}$ & $\begin{array}{c}100.00 \\
(97.50-100.00)\end{array}$ & $\begin{array}{c}100.00 \\
(97.50-100.00)\end{array}$ & $\begin{array}{l}129.87 \\
<.000\end{array}$ & 0.419 \\
\hline At home & $\begin{array}{c}95.83 \\
(87.50-100.00)\end{array}$ & $\begin{array}{c}100.00 \\
(100.00-100.00)\end{array}$ & $\begin{array}{c}100.00 \\
(100.00-100.00)\end{array}$ & $\begin{array}{l}96.51 \\
<.000\end{array}$ & 0.311 \\
\hline In the community & $\begin{array}{c}87.50 \\
(75.00-100.00)\end{array}$ & $\begin{array}{c}100.00 \\
(100.00-100.00)\end{array}$ & $\begin{array}{c}100.00 \\
(100.00-100.00)\end{array}$ & $\begin{array}{l}101.01 \\
<.000\end{array}$ & 0.326 \\
\hline At school & $\begin{array}{c}95.00 \\
(80.00-100.00)\end{array}$ & $\begin{array}{c}100.00 \\
(100.00-100.00)\end{array}$ & $\begin{array}{c}100.00 \\
(100.00-100.00)\end{array}$ & $\begin{array}{r}107.03 \\
<.000\end{array}$ & 0.345 \\
\hline In the environment & $\begin{array}{c}90.00 \\
(75.00-100.00)\end{array}$ & $\begin{array}{c}100.00 \\
(95.00-100.00)\end{array}$ & $\begin{array}{c}100.00 \\
(95.00-100.00)\end{array}$ & $\begin{array}{c}96.39 \\
<.000\end{array}$ & 0.311 \\
\hline \multicolumn{6}{|c|}{ Self-report $10-18(N=155)$} \\
\hline Total & $\begin{array}{c}87.50 \\
(75.00-93.75)\end{array}$ & $\begin{array}{c}97.50 \\
(92.50-100.00)\end{array}$ & $\begin{array}{c}97.50 \\
(93.75-100.00)\end{array}$ & $\begin{array}{l}116.11 \\
<.000\end{array}$ & 0.375 \\
\hline At home & $\begin{array}{c}87.50 \\
(79.17-95.83)\end{array}$ & $\begin{array}{c}100.00 \\
(91.67-100.00)\end{array}$ & $\begin{array}{c}100.00 \\
(95.83-100.00)\end{array}$ & $\begin{array}{l}92.99 \\
<.000\end{array}$ & 0.300 \\
\hline In the community & $\begin{array}{c}81.25 \\
(66.67-93.75)\end{array}$ & $\begin{array}{c}100.00 \\
(93.75-100.00)\end{array}$ & $\begin{array}{c}100.00 \\
(93.75-100.00)\end{array}$ & $\begin{array}{l}95.12 \\
<.000\end{array}$ & 0.307 \\
\hline At school & $\begin{array}{c}90.00 \\
(75.00-100.00)\end{array}$ & $\begin{array}{c}100.00 \\
(95.00-100.00)\end{array}$ & $\begin{array}{c}100.00 \\
(100.00-100.00)\end{array}$ & $\begin{array}{c}122.53 \\
<.000\end{array}$ & 0.395 \\
\hline In the environment & $\begin{array}{c}85.00 \\
(70.00-95.00)\end{array}$ & $\begin{array}{c}100.00 \\
(90.00-100.00)\end{array}$ & $\begin{array}{c}95.00 \\
(90.00-100.00)\end{array}$ & $\begin{array}{l}80.73 \\
<.000\end{array}$ & 0.260 \\
\hline
\end{tabular}

Abbreviations: CASP, Child and Adolescent Scale of Participation; mTBI, mild traumatic brain injury; $T_{0}, 2$ weeks post-mTBI; $T_{1}, 3$ months post-mTBI; $T_{2}, 6$ months post-mTBI.

\section{DISCUSSION}

The present study identified a general improvement in activities and participation in different settings and for several activity domains during the first 6 months after childhood mTBI. In accordance with our expectations, the level of activities and participation was lowest at 2 weeks postinjury, increased up to 3 months postinjury, and stabilized up to 6 months postinjury in most settings and activity domains. Strikingly, caregivers evaluated their child's level of activities and participation in different settings more positively than the evaluation of the children themselves. The course of activities and participation over time after mTBI in different settings and on several activity domains was, in accordance with our expectations, positively correlated.

\section{Explanations of the findings}

The finding that activities and participation improve over time after mTBI is largely in agreement with previous findings. ${ }^{12,13} \mathrm{We}$ found that in most settings, the level of activities and participation stabilized between 3 and 6 months postinjury. Caregivers, however, reported that the level of activities and participation of their child at home had increased significantly between 2 weeks and 3 months as well as between 3 and 6 months postinjury. The notion that caregivers may set higher priorities for returning to school and resuming activities in the community than resuming activities at home (eg, cleaning their room) may explain the further improvement in this setting after 3 months postinjury. Although activities and participation improve over time, it was found 
TABLE 3 Full or deviant outcome on activities and participation in different settings over time post-mTBI

\begin{tabular}{|c|c|c|c|c|c|c|}
\hline \multirow[b]{2}{*}{ CASPa Setting } & \multicolumn{2}{|c|}{$T_{0}$} & \multicolumn{2}{|c|}{$T_{1}$} & \multicolumn{2}{|c|}{$T_{2}$} \\
\hline & $\begin{array}{c}\text { Deviant, } \\
n(\%)\end{array}$ & Full, $n(\%)$ & $\begin{array}{c}\text { Deviant, } \\
n(\%)\end{array}$ & Full, $n(\%)$ & $\begin{array}{c}\text { Deviant, } \\
n(\%)\end{array}$ & Full, $n(\%)$ \\
\hline \multicolumn{7}{|c|}{ Caregiver report 6-18 $(N=231)$} \\
\hline Total & $172(74.5)$ & $59(25.5)$ & $88(38.1)$ & $143(61.9)$ & $78(33.8)$ & $153(66.2)$ \\
\hline At home & $118(51.1)$ & $113(48.9)$ & $51(22.1)$ & 180 (77.9) & $28(12.1)$ & $203(87.9)$ \\
\hline In the community & $129(55.8)$ & $102(44.2)$ & $50(21.6)$ & $181(78.4)$ & $34(14.7)$ & $197(85.3)$ \\
\hline At school & $122(52.8)$ & $109(47.2)$ & 38 (16.5) & 193 (83.5) & $30(13.0)$ & $201(87.0)$ \\
\hline In the environment & 135 (58.4) & $96(41.6)$ & $62(26.8)$ & 169 (73.2) & $60(26.0)$ & $171(74.0)$ \\
\hline \multicolumn{7}{|c|}{ Caregiver report $10-18(N=155)$} \\
\hline Total & $124(80.0)$ & $31(20.0)$ & $63(40.6)$ & $92(59.4)$ & $56(36.1)$ & 99 (63.9) \\
\hline At home & $88(56.8)$ & $67(43.2)$ & $34(21.9)$ & $121(78.1)$ & $22(14.2)$ & $133(85.8)$ \\
\hline In the community & $96(61.9)$ & $59(38.1)$ & $37(23.9)$ & $118(76.1)$ & $29(18.7)$ & 126 (81.3) \\
\hline At school & $90(58.1)$ & 65 (41.9) & $27(17.4)$ & $128(82.6)$ & $22(14.2)$ & $133(85.8)$ \\
\hline In the environment & $98(63.2)$ & $57(36.8)$ & $42(27.1)$ & $113(72.9)$ & $43(27.7)$ & 112 (72.3) \\
\hline \multicolumn{7}{|c|}{ Self-report $10-18(N=155)$} \\
\hline Total & $147(94.8)$ & $8(5.2)$ & $94(60.6)$ & $61(39.4)$ & 99 (63.9) & $56(36.1)$ \\
\hline At home & $123(79.4)$ & $32(20.6)$ & $58(37.4)$ & $97(62.6)$ & $59(38.1)$ & $96(61.9)$ \\
\hline In the community & 123 (79.4) & $32(20.6)$ & $62(40.0)$ & $93(60.0)$ & $53(34.2)$ & $102(65.8)$ \\
\hline At school & 105 (67.7) & 50 (32.3) & $41(26.5)$ & 114 (73.5) & $31(20.0)$ & $124(80.0)$ \\
\hline In the environment & 123 (79.4) & $32(20.6)$ & $74(47.7)$ & $81(52.3)$ & $80(51.6)$ & 75 (48.4) \\
\hline
\end{tabular}

Abbreviations: CASP, Child and Adolescent Scale of Participation; mTBI, mild traumatic brain injury; $T_{0}, 2$ weeks post-mTBI; $T_{1}, 3$ months post-mTBI; $T_{2}, 6$ months post-mTBI.

${ }^{a} 1=$ maximum score $(100.00)$ on the CASP representing full recovery; $0=$ score $(<100.00)$ on the CASP representing deviant functioning.

that between $33.8 \%$ and $63.9 \%$ of the children with mTBI still participate less in than their peers did at 6 months postinjury. The difference in percentages was explained by the chosen perspective, resulting in a more positive evaluation of the child's level of activities and participation from the caregivers' perspective than from the children's perspective for children aged 10 to 18 years. This finding does not accord with findings from another study, in which children seemed to evaluate their level of activities and participation higher in than their caregivers, ${ }^{21}$ but this mixed-sample study did not differentiate for mTBI. An explanation for the more positive evaluation of the parents could be that they mostly observe their children at home while more complex activities are required at school. It is possible that mTBI affects the more complex activities to a greater extent.

Concerning child motivation, we observed that high school-aged children seemed less motivated and used the injury more often as an excuse in comparison with elementary school-aged children, who preferred to return to activities and participation as soon as possible after the injury. Child motivation is one of the facilitating factors for good participation after TBI. ${ }^{33}$ Our observation is in line with general behavior in puberty, during which less motivation for things that have to be done (eg, homework, dishes) is more common than in younger children. Another explanation may be that younger children spend more time with their parents than do older children. For younger children, caregivers may therefore have a more complete view of their child's functioning than their view of older children who commonly spend more time with peers. Caregivers may assume that their older child has successfully returned to activities and participation in all settings, because they are doing so at home, while the child may experience that, for example, at school, participation is more difficult due to problems with concentrating.

\section{Strengths and limitations}

This study has several strengths. First, we examined a large population of children with $\mathrm{mTBI}$ and evaluated children of all school ages (6-18 years) as well as their caregivers. Second, the outcome instruments used in this study were based largely on the ICF-CY and recommended by the interagency Pediatric Outcome Workgroup. $^{29}$

Some limitations, however, must be acknowledged. First, as children and adolescents with mTBI were recruited from emergency departments, our sample may not be representative of the larger population, as this excludes those who do not receive acute medical care. Population research is needed to find out how these children function on the level of activities and participation. 
TABLE 4 Cochran's $Q$ tests and McNemar's tests for outcome on activities and participation in different settings over time post-mTBI ${ }^{a}$

\begin{tabular}{|c|c|c|c|c|}
\hline CASP Setting & $\underset{P}{\text { Cochran's } \mathbf{Q}}$ & $\begin{array}{c}T_{0} \text { vs } T_{1} \\
\chi^{2} P \\
\text { OR }^{b}\end{array}$ & $\begin{array}{c}T_{1} \text { vs } T_{2} \\
\chi^{2} P \\
\text { OR }^{b}\end{array}$ & $\begin{array}{c}T_{0} \text { vs } T_{2} \\
\chi^{2} P \\
\text { OR }^{b}\end{array}$ \\
\hline \multicolumn{5}{|c|}{ Caregiver report 6-18 $(N=231)$} \\
\hline Total & $\begin{array}{l}116.73 \\
<.000\end{array}$ & $\begin{array}{l}68.89 \\
<.000 \\
5.754\end{array}$ & $\begin{array}{c}1.35 \\
.245 \\
6.374\end{array}$ & $\begin{array}{l}75.87 \\
<.000 \\
2.349\end{array}$ \\
\hline At home & $\begin{array}{l}101.69 \\
<.000\end{array}$ & $\begin{array}{l}41.49 \\
<.000 \\
1.865\end{array}$ & $\begin{array}{c}10.30 \\
.001 \\
4.583\end{array}$ & $\begin{array}{l}74.73 \\
<.000 \\
2.920\end{array}$ \\
\hline In the community & $\begin{array}{l}114.98 \\
<.000\end{array}$ & $\begin{array}{l}56.86 \\
<.000 \\
3.170\end{array}$ & $\begin{array}{c}5.11 \\
.024 \\
10.296\end{array}$ & $\begin{array}{l}74.15 \\
<.000 \\
1.675\end{array}$ \\
\hline At school & $\begin{array}{c}123.68 \\
<.000\end{array}$ & $\begin{array}{l}71.76 \\
<.000 \\
5.720\end{array}$ & $\begin{array}{c}1.11 \\
.292 \\
6.846\end{array}$ & $\begin{array}{l}73.94 \\
<.000 \\
1.833\end{array}$ \\
\hline In the environment & $\begin{array}{l}88.37 \\
<.000\end{array}$ & $\begin{array}{l}55.74 \\
<.000 \\
7.543\end{array}$ & $\begin{array}{l}.02 \\
.892 \\
7.559\end{array}$ & $\begin{array}{l}54.22 \\
<.000 \\
4.684\end{array}$ \\
\hline \multicolumn{5}{|c|}{ Caregiver report $10-18(N=142)$} \\
\hline Total & $\begin{array}{l}83.11 \\
<.000\end{array}$ & $\begin{array}{l}49.32 \\
<.000 \\
3.545\end{array}$ & $\begin{array}{c}.80 \\
.371 \\
5.468\end{array}$ & $\begin{array}{l}53.44 \\
<.000 \\
1.816\end{array}$ \\
\hline At home & $\begin{array}{l}78.89 \\
<.000\end{array}$ & $\begin{array}{l}35.11 \\
<.000 \\
1.302\end{array}$ & $\begin{array}{l}3.78 \\
.052 \\
6.055\end{array}$ & $\begin{array}{l}55.59 \\
<.000 \\
2.969\end{array}$ \\
\hline In the community & $\begin{array}{l}81.98 \\
<.000\end{array}$ & $\begin{array}{l}42.58 \\
<.000 \\
1.917\end{array}$ & $\begin{array}{c}1.53 \\
.216 \\
7.508\end{array}$ & $\begin{array}{l}51.25 \\
<.000 \\
1.462\end{array}$ \\
\hline At school & $\begin{array}{l}92.67 \\
<.000\end{array}$ & $\begin{array}{l}51.25 \\
<.000 \\
2.993\end{array}$ & $\begin{array}{c}0.552 \\
.458 \\
5.686\end{array}$ & $\begin{array}{l}54.74 \\
<.000 \\
1.657\end{array}$ \\
\hline In the environment & $\begin{array}{l}66.26 \\
<.000\end{array}$ & $\begin{array}{l}44.49 \\
<.000 \\
4.935\end{array}$ & $\begin{array}{c}0.00 \\
1.000 \\
4.819\end{array}$ & $\begin{array}{l}37.87 \\
<.000 \\
2.028\end{array}$ \\
\hline \multicolumn{5}{|c|}{ Self-report 10-18 $(N=142)$} \\
\hline Total & $\begin{array}{l}59.06 \\
<.000\end{array}$ & $\begin{array}{l}47.44 \\
<.000 \\
5.018\end{array}$ & $\begin{array}{r}0.28 \\
.596 \\
2.531\end{array}$ & $\begin{array}{l}36.82 \\
<.000 \\
.574\end{array}$ \\
\hline At home & $\begin{array}{l}80.80 \\
<.000\end{array}$ & $\begin{array}{l}50.57 \\
<.000 \\
2.055\end{array}$ & $\begin{array}{c}0.00 \\
1.000 \\
5.265\end{array}$ & $\begin{array}{l}49.61 \\
<.000 \\
2.125\end{array}$ \\
\hline In the community & $\begin{array}{l}81.33 \\
<.000\end{array}$ & $\begin{array}{l}44.44 \\
<.000 \\
1.611\end{array}$ & $\begin{array}{c}1.56 \\
.212 \\
7.123\end{array}$ & $\begin{array}{l}51.75 \\
<.000 \\
.990\end{array}$ \\
\hline At school & $\begin{array}{l}93.90 \\
<.000\end{array}$ & $\begin{array}{l}49.61 \\
<.000 \\
2.406\end{array}$ & $\begin{array}{l}2.13 \\
.144 \\
5.060\end{array}$ & $\begin{array}{l}60.56 \\
<.000 \\
1.820\end{array}$ \\
\hline In the environment & $\begin{array}{l}43.29 \\
<.000\end{array}$ & $\begin{array}{l}32.45 \\
<.000 \\
2.005\end{array}$ & $\begin{array}{c}0.46 \\
.496 \\
3.542\end{array}$ & $\begin{array}{l}24.16 \\
<.000 \\
1.270\end{array}$ \\
\hline
\end{tabular}

Abbreviations: CASP, Child and Adolescent Scale of Participation; mTBI, mild traumatic brain injury; $T_{0}, 2$ weeks post-mTBI; $T_{1}, 3$ months post-mTBI; $T_{2}, 6$ months post-mTBI.

${ }^{a}$ Exact sig. (2-tailed)

${ }^{b}$ Mantel-Haenszel common odds ratio estimate. 
TABLE 5 Outcome on activities and participation for several activity domains over time post-mTBI $(\mathrm{N}=231)$

\begin{tabular}{|lrrr|}
\hline \multicolumn{1}{|c}{ CAPE Domain } & $\boldsymbol{T}_{\mathbf{0}}$, mean (SD) & $\boldsymbol{T}_{\mathbf{1}}$, mean (SD) & $\mathbf{T}_{\mathbf{2}}$, mean (SD) \\
\hline Total & $15.93(5.45)$ & $22.77(5.27)$ & $21.92(5.03)$ \\
Recreational & $5.50(2.27)$ & $6.74(2.50)$ & $6.39(2.45)$ \\
Active physical & $1.55(1.27)$ & $2.55(1.07)$ & $2.61(1.16)$ \\
Social & $3.54(1.74)$ & $5.67(1.61)$ & $5.50(1.83)$ \\
Skill-based & $0.98(1.15)$ & $1.87(1.29)$ & $1.68(1.28)$ \\
Self-improvement & $3.23(1.50)$ & $4.25(1.63)$ & $4.13(1.63)$ \\
\hline
\end{tabular}

Abbreviations: CAPE, Children's Assessment of Participation and Enjoyment; mTBI, mild traumatic brain injury; $T_{0}, 2$ weeks post-mTBI; $T_{1}, 3$ months post-mTBI; $T_{2}, 6$ months post-mTBI.

Second, a relatively large number of children who were eligible for participation in the study could not be reached, which influences the external validity. From the number of eligible participants who were reached, however, almost $80 \%$ chose to participate. In checking whether the children in the intervention group $(n=$ 60) differed in terms of baseline characteristics from the control group in our intervention study, no significant differences were found. Our ethics regulations do not permit us to collect data on excluded participants and therefore we cannot test differences for this group. Third, neuroimaging findings of our sample are not available because these data are not gathered systematically at the emergency departments, leading to many missing data points. ${ }^{4}$ A direct comparison with other studies on the proportion of children with complicated/uncomplicated mTBI could not be made. However, for the purposes of the present study, these data are less relevant because they have not been found to predict outcome on the level of activities and participation in children with brain injury of mixed severity and etiology. Finally, children with histories of learning disability, attention-deficit/hyperactivity disorder, or similar problems are known to be at a relatively increased risk for suboptimal outcomes. These conditions were not taken as exclusion criteria. However, we measured preinjury behavioral functioning with the CBCL (see Table 1) and only $4.3 \%$ were severely impaired before the injury.

\section{Added value and recommendations}

This study adds to the literature on the ceiling effect of the CASP. For a better understanding, we recommend using dichotomized scores to interpret results. The CASP seems to be a reliable instrument to assess activities and participation in children with more severe head injuries but may not be the most sensitive measure for children with mTBI. Recently, it was shown that the CASP is responsive to change over time, particularly in more severe TBI. ${ }^{19}$ Validated instruments to measure activities and participation in children with pediatric TBI, or even mTBI, are scarce. Although the CAPE was validated in children with physical disabilities, it has also been used in studies on children with ABI before. ${ }^{20,34}$ We were the first to use the CAPE in children with mTBI specifically and therefore reference material is currently lacking. Our detailed description of data in a large

TABLE 6 Repeated-measures analysis of variance and post hoc analyses for outcome on activities and participation for several activity domains over time post-mTBI $(\mathrm{N}=231)$

\begin{tabular}{|c|c|c|c|c|c|c|c|c|}
\hline \multirow[t]{2}{*}{ CAPE domain } & \multicolumn{4}{|c|}{ RMA } & \multirow[b]{2}{*}{$\eta_{\mathrm{p}}{ }^{2}$} & \multicolumn{3}{|c|}{ Post hoc test (Bonferroni correction) } \\
\hline & $d f_{M}$ & $d f_{R}$ & $\boldsymbol{F}$ & $\boldsymbol{P}$ & & $T_{0}$ vs $T_{1}, P$ & $T_{1}$ vs $T_{2}, P$ & $T_{0}$ vs $T_{2}, P$ \\
\hline Total & 1.82 & 417.50 & 218.06 & $<.000$ & 0.487 & $<.000$ & .054 & $<.000$ \\
\hline Recreational & 1.97 & 451.95 & 56.21 & $<.000$ & 0.196 & $<.000$ & .005 & $<.000$ \\
\hline Active physical & 1.85 & 425.60 & 98.15 & $<.000$ & 0.299 & $<.000$ & 1.000 & $<.000$ \\
\hline Social & 1.87 & 429.43 & 191.71 & $<.000$ & 0.455 & $<.000$ & .295 & $<.000$ \\
\hline Skill-based & 1.95 & 447.81 & 54.44 & $<.000$ & 0.191 & $<.000$ & .075 & $<.000$ \\
\hline Self-improvement & 1.98 & 455.48 & 47.27 & $<.000$ & 0.170 & $<.000$ & .862 & $<.000$ \\
\hline
\end{tabular}

Abbreviations: CAPE, Children's Assessment of Participation and Enjoyment; mTBI, mild traumatic brain injury; $\eta \mathrm{p}^{2}$, partial eta squared; RMA, repeated-measures analysis of variance; $T_{0}, 2$ weeks post-mTBI; $T_{1}, 3$ months post-mTBI; $T_{2}, 6$ months post-mTBI.

www.headtraumarehab.com 
sample adds to the existing knowledge base, and since the CAPE could discriminate levels of activities and participation in several activity domains over time, we believe that this supports use of the instrument in a pediatric mTBI sample. In addition, to the best of our knowledge, better instruments to assess activities and participation in children after mTBI do not yet exist. We emphasize the importance of developing an instrument that is more sensitive in distinguishing levels of activities and participation among children with mild brain injuries. The use of such an instrument in clinical settings could be restricted to those who do not return to normal or preinjury levels of activities and participation, after its capacity for discrimination is established. In addition, in order to restrict the use of such an instrument to those who will not return to normal or preinjury levels and who may need early interventions, information on predictors is needed. Predictors of outcome in terms of activities and participation have also not been studied for children with mTBI specifically.

\section{CONCLUSION}

This is the first large-sample, prospective, longitudinal study of a homogeneous sample of children with only mTBI. Activities and participation were found to increase over time in different settings and for several activity domains after mTBI in children. For a substantial number of children, however, the levels of activities and participation at 6 months post-mTBI fell below those of peers. Future studies should investigate predictors for activities and participation to provide insight into those children who are at risk for long-term problems and who may benefit from early interventions. Furthermore, population research is needed because at this point we only have information on those children with mTBI who were admitted to the emergency departments of hospitals. Since outcomes for activities and participation differ between the perspective of the caregiver and the child, and across domains and settings, we emphasize the importance of investigating predictors from all perspectives.

\section{REFERENCES}

1. Kraus JF, Rock A, Hemyari P. Brain injuries among infants, children, adolescents and young adults. Am J Dis Child. 1990;144(6): 684-691. doi:10.1001/archpedi.1990.02150300082022.

2. McKinlay A, Grace RC, Horwood LJ, Fergusson DM, Ridder EM, MacFarlane MR. Prevalence of traumatic brain injury among children, adolescents and young adults: prospective evidence from a birth cohort. Brain Inj. 2008;22(2):175-181. doi:10.1080/ 02699050801888824.

3. Langlois JA, Rutland-Brown W, Thomas KE. The incidence of traumatic brain injury among children in the United States: differences by race. J Head Trauma Rehabil. 2005;20(3):229-238. doi:10.1097/00001199-200505000-00006.

4. Broers MC, Niermeijer JM, Kotsopolous IAW, et al. Evaluation of management and guideline adherence in children with mild traumatic brain injury. Brain Inj. 2018;32(8):1028-1039. doi:10.1080/02699052.2018.1469047.

5. Taylor HG, Orchinik LJ, Minich N, et al. Symptoms of persistent behavior problems in children with mild traumatic brain injury. J Head Trauma Rehabil. 2015;30(5):302-310. doi:10.1097/htr.0000000000000106.

6. Blinman TA, Houseknecht E, Snyder C, Wiebe DJ, Nance ML. Postconcussive symptoms in hospitalized pediatric patients after mild traumatic brain injury. J Pediatr Surg. 2009;44(6):1223-1228.

7. Hawley CA, Ward AB, Magnay AR, Long J. Outcomes following childhood head injury: a population study. J Neurol Neurosurg Psychiatry. 2004;75(5):737-742. doi:10.1136/jnnp.2003.020651.

8. Barlow KM, Crawford S, Stevenson A, Sandhu SS, Belanger F, Dewey D. Epidemiology of postconcussion syndrome in pediatric mild traumatic brain injury. Pediatrics. 2010;126(2):e374e381. doi:10.1542/peds.2009-0925.

9. Ruff R. Two decades of advances in understanding of mild traumatic brain injury. J Head Trauma Rehabil. 2005;20(1):5-18. doi:10.1097/00001199-200501000-00003.

10. van Heugten CM, Renaud MI, Resch C. The role of early intervention in improving the level of activities and participation in youths after mild traumatic brain injury: a scoping review. J Concussion. 2017;2(3):CNC38. doi:10.2217/cnc-2016-0030.
11. Renaud I, Lambregts SA, de Kloet A, Catsman-Berrevoets CE, van De Port I, van Heugten CM. Activities and participation of children and adolescents after mild traumatic brain injury and the effectiveness of an early intervention (Brains Ahead!): study protocol for a cohort study with a nested randomised controlled trial. Trials. 2016;17(1):236. doi:10.1186/s13063-0161357-6.

12. Bedell GM, Dumas HM. Social participation of children and youth with acquired brain injuries discharged from inpatient rehabilitation: a follow-up study. Brain Inj. 2004;18(1):65-82. doi:10.1080/0269905031000110517.

13. De Kloet AJ, Gijzen R, Braga LW, Meesters JJ, Schoones JW, Vliet Vlieland TP. Determinants of participation of youth with acquired brain injury: a systematic review. Brain Inj. 2015;29(10):11351145. doi:10.3109/02699052.2015.1034178.

14. van Tol E, Gorter JW, DeMatteo C, Meester-Delver A. Participation outcomes for children with acquired brain injury: a narrative review. Brain Inj. 2011;25(13/14):1279-1287. doi:10.3109/02699052.2011.613089.

15. Foo WS, Galvin J, Olsen J. Participation of children with ABI and the relationship with discharge functional status. Dev Neurorehabil. 2012;15(1):1-12. doi:10.3109/17518423.2011.623142.

16. Galvin J, Froude EH, McAleer J. Children's participation in home, school and community life after acquired brain injury. Aust Occup Ther J. 2010;57(2):118-126. doi:10.1111/j.1440-1630. 2009.00822.x.

17. Catroppa C, Crossley L, Hearps SJ, et al. Social and behavioral outcomes: pre-injury to six months following childhood traumatic brain injury. J Neurotrauma. 2015;32(2):109-115. doi:10.1089/neu.2013.3276.

18. Law M, Anaby D, DeMatteo C, Hanna S. Participation patterns of children with acquired brain injury. Brain Inj. 2011;25(6):587-595. doi:10.3109/02699052.2011.572945.

19. Golos A, Bedell G. Responsiveness and discriminant validity of the Child and Adolescent Scale of Participation across three years for children and youth with traumatic brain injury. Dev Neurorebabil. 2018;21(7):431-438. doi:10.1080/17518423.2017.1342711. 
20. Anaby D, Law M, Hanna S, Dematteo C. Predictors of change in participation rates following acquired brain injury: results of a longitudinal study. Dev Med Child Neurol. 2012;54(4):339-346. doi:10.1111/j.1469-8749.2011.04204.x.

21. McDougall J, Bedell G, Wright V. The youth report version of the Child and Adolescent Scale of Participation (CASP): assessment of psychometric properties and comparison with parent report. Child Care Health Dev. 2013;39(4):512-522. doi:10.1111/cch.12050.

22. De Kloet AJ, Berger MA, Bedell GM, Catsman-Berrevoets CE, van Markus-Doornbosch F, Vliet Vlieland TP. Psychometric evaluation of the Dutch language version of the Child and Family Follow-up Survey. Dev Neurorehabil. 2015;18(6):357-364. doi:10.3109/17518423.2013.850749.

23. Desha LN, Ziviani JM. Use of time in childhood and adolescence: a literature review on the nature of activity participation and depression. Aust Occup Ther J. 2007;54(1):4-10. doi:10.1111/j.14401630.2006.00649.x.

24. Kristman VL, Borg J, Godbolt AK, et al. Methodological issues and research recommendations for prognosis after mild traumatic brain injury: results of the International Collaboration on Mild Traumatic Brain Injury Prognosis. Arch Phys Med Rehabil. 2014;95(3)(suppl):S265-S277. doi:10.1016/j.apmr.2013. 04.026.

25. Achenbach TM, Becker A, Döpfner M, et al. Multicultural assessment of child and adolescent psychopathology with ASEBA and SDQ instruments: research findings, applications, and future directions. J Child Psychol Psychiatry. 2008;49(3):251-275. doi:10.1111/j.1469-7610.2007.01867.x.

26. Bedell G. Further validation of the Child and Adolescent Scale of Participation (CASP). Dev Neurorehabil. 2009;12(5):342-351. doi:10.3109/17518420903087277.
27. Bult MK, Verschuren O, Gorter JW, Jongmans MJ, Piskür B, Ketelaar M. Cross-cultural validation of the Children's Assessment of Participation and Enjoyment (CAPE) in children with and without physical disabilities. Clin Rehabil. 2010;24(9):843-853. doi:10.1111/cch.12012.

28. Imms C. Review of the children's assessment of participation and enjoyment and the preferences for activity of children. Phys Occup Ther Pediatr. 2008;28(4):389-404. doi:10.1080/ 01942630802307135

29. McCauley SR, Wilde EA, Anderson VA, et al. Recommendations for the use of common outcome measures in pediatric traumatic brain injury research. J Neurotrauma. 2012;29(4):678-705. doi:10.1089/neu.2011.1838.

30. World Health Organization. International Classification of Functioning, Disability and Health. Geneva, Switzerland: World Health Organization; 2001.

31. Moulaert VRM, van Heugten CM, Gorgels TPM, Wade DT, Verbunt JA. Long-term outcome after survival of a cardiac arrest: a prospective longitudinal cohort study. Neurorehabil Neural Repair. 2017;31(6):530-539. doi:10.1177/1545968317697032.

32. Cohen J. Statistical Power Analysis for the Behavioral Sciences. 2nd ed. Hillsdale, NJ: Lawrence Erlbaum Associates; 1988.

33. Thompson M, Elliot C, Willis C, et al. Can, want and try: parents' viewpoints regarding the participation of their child with an acquired brain injury. PLoS One. 2016;11(7):e0157951. doi:10.1371/journal.pone.0157951.

34. Connell T, Paterson J, Roberts RM, Raghavendra P, Sawyer M, Russo RN. Clinician modifiable factors associated with better quality of life in children with acquired brain injury undergoing rehabilitation. Brain Inj. 2018;32(4):423-430 doi:10.1080/02699052.2018.1429661. 
APPENDIX. Wilcoxon's Signed-Rank Test for Outcome on Activities and Participation in Different Settings Over Time PostmTBI

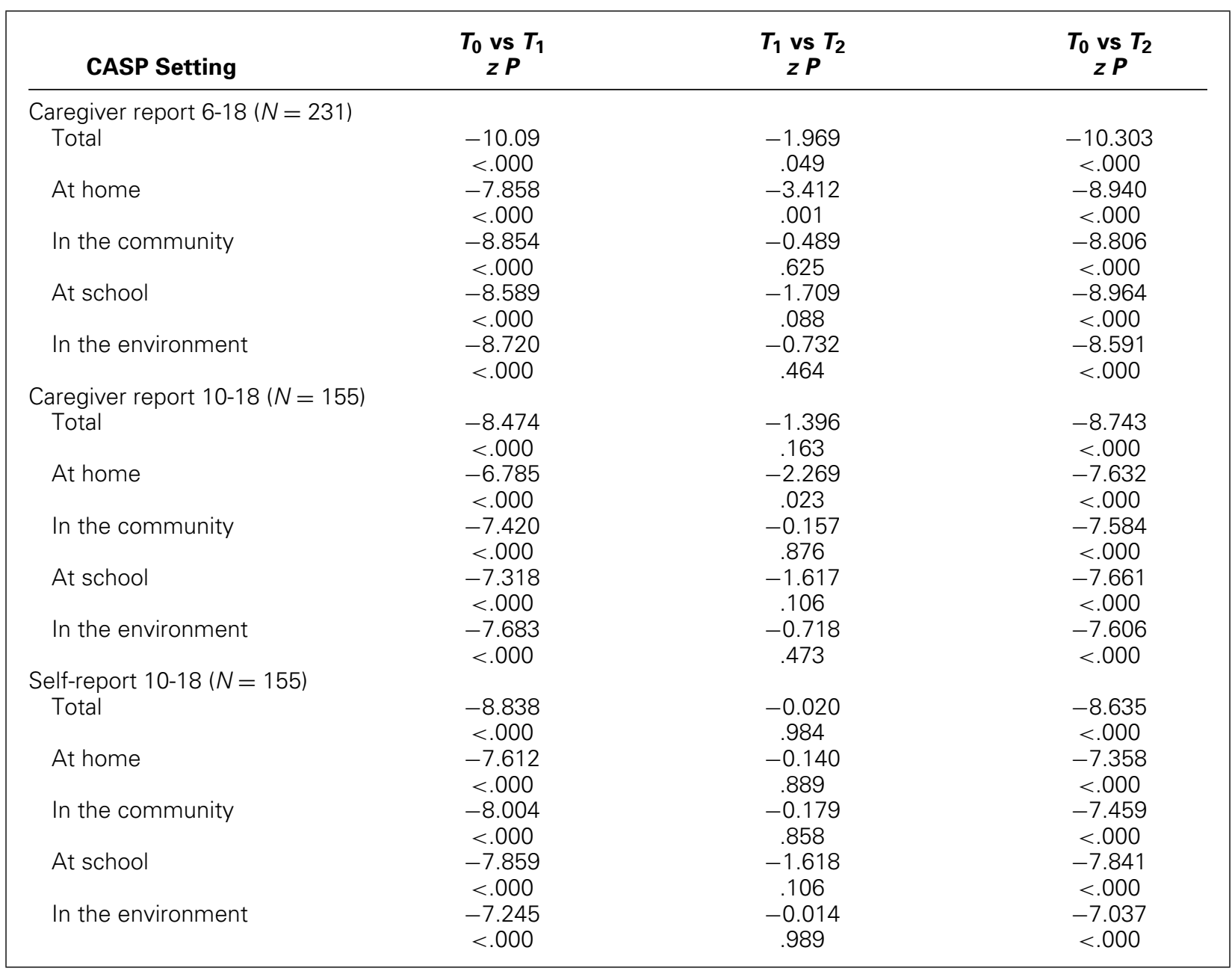

Abbreviations: CASP, Child and Adolescent Scale of Participation; mTBI, mild traumatic brain injury; $T_{0}, 2$ weeks post-mTBI; $T_{1}, 3$ months post-mTBI; $T_{2}, 6$ months post-mTBI. 